\title{
Cost-related nonadherence to prescribed medicines among older Canadians in 2014: a cross-sectional analysis of a telephone survey
}

\author{
Augustine Lee BA, Steve Morgan PhD
}

Abstract

Background: Canadians receive universal coverage for medically necessary hospital and physician services, but pharmaceutical coverage is incomplete. We sought to assess the effects of cost on access to medicines among older Canadians using data from a large survey conducted in 2014.

Methods: This is a cross-sectional analysis of data from the Commonwealth Fund's 2014 International Health Policy Survey of Older Adults. Our primary outcome variable was self-reported cost-related nonadherence in the form of either not filling a prescription or skipping doses within the last 12 months because of out-of-pocket costs. We computed sample-weighted estimates of the population prevalence of cost-related nonadherence and conducted logistic regression analyses to determine associated factors.

Results: We estimate that the prevalence of cost-related nonadherence in 2014 among Canadians aged 55 years and older was 8.3\% (about 1 in 12). The population prevalence and adjusted odds of cost-related nonadherence was significantly higher among Canadians who were younger, in worse health, poorer or without private health insurance. Regional differences in population prevalence of cost-related nonadherence were not significant. The only provincial or regional difference in the adjusted odds of cost-related nonadherence was that residents of Quebec aged 55-64 years were about half as likely to report nonadherence as similarly aged residents of Ontario, our reference province (adjusted odds ratio 0.49, 95\% confidence interval 0.29-0.82).

Interpretation: The financial accessibility of prescription medicines still is a substantial public health issue in Canada that affects 1 in 12 Canadians older than 55 years of age. Older Canadians at greatest risk of cost-related nonadherence to prescribed treatments are those with low incomes and those without private insurance to cover costs not covered by public programs.

U niversal access to necessary medicines is one of the measurable goals of the United Nations drive for universal health coverage in all countries. ${ }^{1}$ Like citizens of almost all other advanced economies, Canadians receive universal coverage for medically necessary hospital care and physician services. But pharmaceutical coverage in Canada is incomplete, with many patients falling through the cracks of what has been described as a "patchwork" of public and private drug plans in each province and territory., ${ }^{2,3}$ Canadian and American studies have shown that levels of access to prescription drugs are correlated with levels of coverage for their costs. ${ }^{4-6}$ Studies have also shown that financial barriers to accessing necessary medications are correlated with poorer health outcomes and increased use and cost of other health services. ${ }^{7,8}$

Previous studies have indicated that $5 \%-10 \%$ of Canadians face cost-related barriers to adherence to prescribed medications. ${ }^{9-12}$ The most recent of these studies are based on data from 2007..$^{9,12}$ As growing attention is being paid to pharmaceutical coverage in Canada, more current estimates of financial barriers are needed. It is possible that access to medicines has changed in Canada since 2007 owing to changes in public drug coverage, changing needs for medicines, changes in disposable income and even changes in the price of medications now that many more generic drugs are available in Canada at far lower cost than were available in 2007.

Competing interests: Steve Morgan reports grants from the Canadian Institutes of Health Research and the Commonwealth Fund during the conduct of the study. No other competing interests were declared.

This article has been peer reviewed.

Correspondence to: Steve Morgan, steve.morgan@ubc.ca CMAJ Open 2017. DOI:10.9778/cmajo.20160126 
The purpose of this study was to analyze more recent data concerning cost-related nonadherence in Canada and to analyze differences in rates across provinces with different structures of public drug benefits. We specifically aimed to determine whether rates of cost-related nonadherence in Canada are still significant, whether they differed by age, income and insurance coverage of patients, and whether there were significant regional variations in rates across Canada.

\section{Methods}

\section{Setting and design}

This is a secondary, cross-sectional analysis of data from the Commonwealth Fund's 2014 International Health Policy Survey of Older Adults. ${ }^{13}$ All study participants were aged 55 years or older and living in the community. All participants were eligible for universal public health insurance for medical and hospital care. Participants' eligibility for either public or private prescription drug coverage would have depended on their age, occupation, income and province of residence. ${ }^{3}$

\section{Data sources}

We used Canadian responses from the 2014 Commonwealth Fund International Health Policy Survey of Older Adults. ${ }^{13}$ This international survey was conducted by telephone and used a common questionnaire across the 11 countries involved. The survey was developed and piloted by the Commonwealth Fund and SSRS, an international survey research firm, with input for health system experts in each country. The final questionnaire was modified for local health system context and languages (English and French for Canada). The survey transcript is available from the Commonwealth Fund. ${ }^{14}$

Participants in the survey had to be aged 55 years or older and living in the community. The Canadian sample (5269 participants) for this survey was larger than all but 1 other country surveyed by the Commonwealth Fund (Sweden, $n=7206$ ). This allowed for comparisons of survey results across provinces and regions of Canada. The response rate for Canada was $28 \%$.

\section{Variables}

Our primary outcome variable was whether a survey respondent had experienced cost-related nonadherence. Respondents who reported that they had received at least 1 prescription and that they had either not filled a prescription or had skipped doses within the last 12 months because of out-ofpocket costs were considered to have experienced cost-related nonadherence. Those who responded that they "did not know" whether they had not filled a prescription or skipped doses because of costs were coded as not having experienced cost-related nonadherence.

Informed by existing literature and models of access to care and health services use, ${ }^{15-17}$ we selected survey questions concerning age, sex, income and health status as potential predictors of cost-related nonadherence. We classified age into 2 groups of primary interest: 55-64 years versus 65 years and older. We included self-reported income using the Common- wealth Fund's definitions of "above average," "average" and "below average." We aggregated self-reported health status into 3 categories: "very good," "good" and either "fair" or "poor." In addition, we included self-reported presence of private health insurance: whether or not respondents answered yes to the survey question, "in addition to government-funded health services, are you currently covered by any private health insurance that you or your family pays for or that an employer or association pays for?"

\section{Comparison groups}

Although the overall Canadian sample was relatively large, the samples from all but the largest provinces were too small to power analyses of factors associated with cost-related nonadherence. We therefore grouped provinces by region and general type of public drug coverage offered. ${ }^{3}$ A summary of the public drug coverage available for people less than 65 years of age and those aged 65 years and older is provided in Appendix 1 (available at www.cmajopen.ca/content /5/1/E40/suppl/DC1).

British Columbia and Manitoba were grouped together as western provinces that offered income-based public coverage, under which age was not a substantial determinant of public drug benefits. Alberta and Saskatchewan were grouped together as western provinces that offer relatively comprehensive public coverage for people more than 65 years of age and more limited (though varied) public coverage for younger residents. Ontario was left as a stand-alone province that offers income-based public coverage for residents less than 65 years of age and relatively comprehensive public coverage for residents aged 65 years and older. Quebec was left as a standalone province that achieved universal coverage through mandatory participation in either public or private insurance plans involving premiums, deductibles and coinsurance. Atlantic provinces were grouped together despite having somewhat varied approaches to public drug coverage.

In all models comparing cost-related nonadherence across regions of Canada, we used residents of Ontario as the reference group.

\section{Statistical methods}

We computed the sample-weighted prevalence of self-reported cost-related nonadherence for each province or region. Weighting was done using the Commonwealth Fund sample weights to reflect general populations in Canada.

We ran sample-weighted logistic regressions to determine the associations between self-reported cost-related nonadherence and potential predictors (age, sex, income and health status). We performed pooled and stratified analyses by province and by age group (age 55-64 yr and age $\geq 65 \mathrm{yr}$ ).

We tested for sensitivity of results to changes in model specification. Furthermore, we tested for sensitivity of results to inclusion of observations with missing data by using multiple imputation to replace missing data for those survey respondents.

For all analyses, a value of $p$ less than 0.05 was considered significant. All analyses were performed using SPSS (Statistics 20). 


\section{OPEN}

\section{Results}

Of the 5269 Canadian respondents to the 2014 Commonwealth Fund International Health Policy Survey of Older Adults, 4690 had complete data for all variables used in our analysis. Table 1 shows demographic features of the study population with complete data, along with accompanying sample-weighted prevalence rates of cost-related nonadherence among the relevant subgroups. Most (69.6\%) of the Canadian respondents to the survey were more than 65 years of age and most (62.8\%) were female. About half of the Canadian respondents described themselves as having below average income.

The estimated prevalence of cost-related nonadherence in 2014 among Canadians aged 55 years and older is $8.3 \%$. The

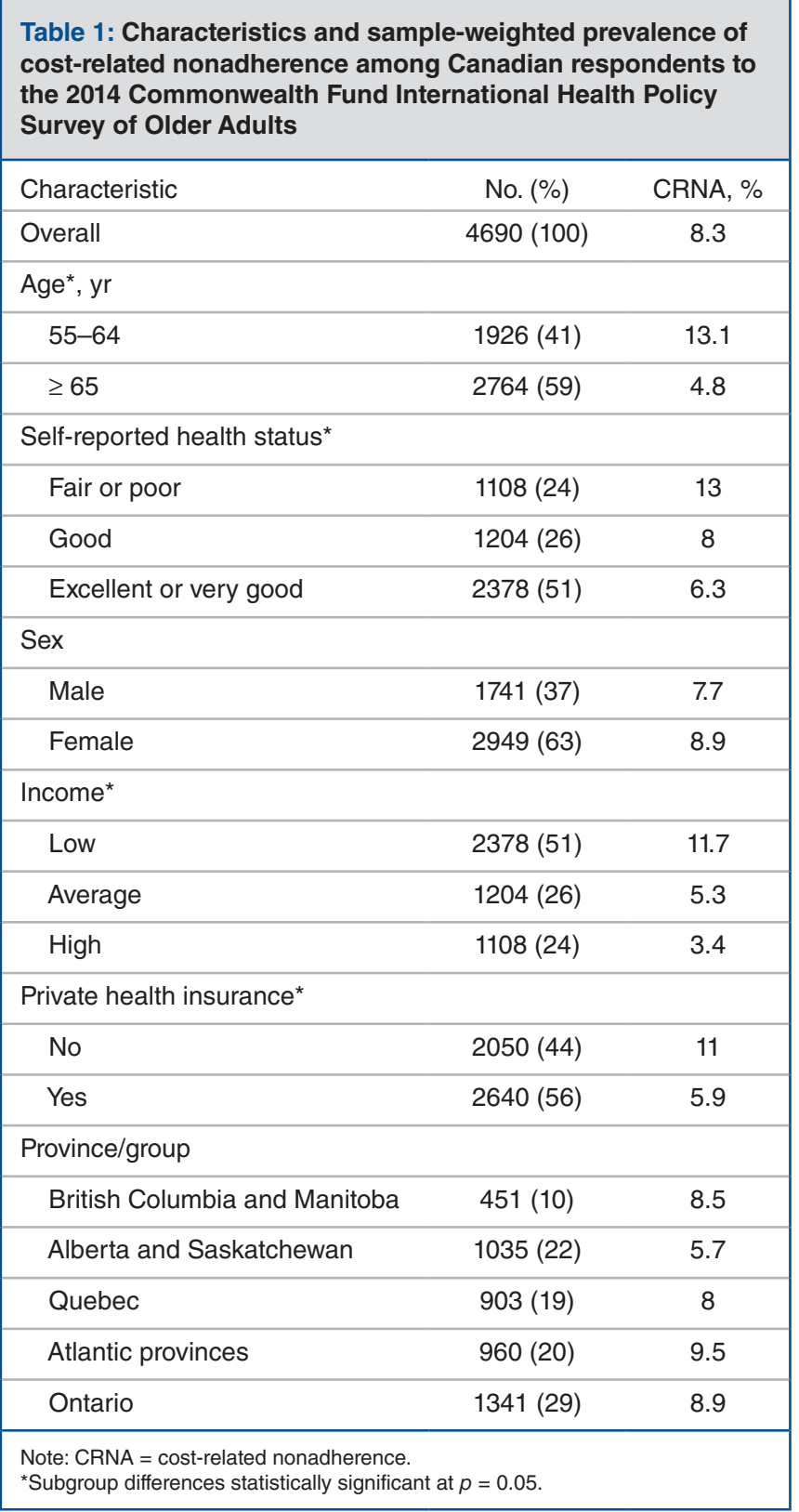

prevalence was significantly higher among Canadians who were younger, in worse health, poorer or without private health insurance. Regionally, the estimated 2014 prevalence of cost-related nonadherence among older adults varied from $5.7 \%$ in Alberta and Saskatchewan to $9.5 \%$ in the Atlantic provinces; however, differences in the regional population prevalence rates were not significant.

Table 2 shows the results of the logistic regression to find variables associated with cost-related nonadherence among all Canadian respondents to the survey - unadjusted odds ratios (ORs) are provided in Appendix 2 (available at www.cmajopen .ca/content/5/1/E40/suppl/DC1). With adjustments for all potential predictors of cost-related nonadherence, Canadians aged 55-64 years were more than 3 times as likely to report cost-related nonadherence than those aged 65 years and older (adjusted OR 3.12, 95\% confidence interval [CI] 2.27-5.40); Canadians who reported having fair or poor health were $75 \%$ more likely to report cost-related nonadherence than someone of very good or excellent health (adjusted OR 1.75, 95\% CI 1.12-2.38); Canadians with lower incomes were more than 3 times as likely to report cost-related nonadherence than those with above average income (adjusted OR 3.59, 95\% CI 2.32-5.55); and Canadians who did not have private health insurance were more than twice as likely to report cost-related nonadherence than those with private insurance (adjusted OR 2.33, 95\% CI 1.56-3.10).

In addition, Table 2 shows the results of the logistic regression stratified by age: age 55-64 years and age 65 years and older. Poor health status and lack of insurance coverage significantly increased the adjusted odds of cost-related nonadherence for each age group. The effect of income, however, was significant for Canadians aged 55-64 years, but not for Canadians aged 65 years and older. The only provincial or regional difference that was significant was that residents of Quebec aged 55-64 years were about half as likely to report cost-related nonadherence as similarly aged residents of Ontario, our reference province (adjusted OR 0.49, 95\% CI 0.29-0.82).

We did not find any significant sex differences in the adjusted odds of cost-related nonadherence in either the pooled or age-stratified models. The direction of significant results in the logistic regression analysis were not affected by imputation for missing data versus dropping incomplete survey responses.

\section{Discussion}

We found that $8.3 \%$ of Canadians aged 55 years and older reported not taking medicines as prescribed because of cost in 2014. The risk of such financial barriers to accessing prescriptions is higher for Canadians who were aged 55-64 years (v. those aged $\geq 65 \mathrm{yr}$ ), had fair or poor health status, and lacked insurance coverage for their prescribed medications. Crude rates of cost-related nonadherence ranged from $5.7 \%$ in Alberta and Saskatchewan to $9.5 \%$ in the Atlantic provinces. However, after adjusting for age, health status, income and insurance coverage, we found little evidence of significant 
regional variations in prevalence of cost-related nonadherence. Most of the variation we found in access to medicines stemmed from other explanatory factors, including health status, income and access to private insurance.

Our results are roughly consistent with previous estimates of cost-related nonadherence for Canada. Two previous studies estimated the prevalence among Canadian adults of all ages to be about $10 \%$ in $2007.9,12$ Our study finds a slightly lower prevalence for Canadians aged 55 years and older in 2014. The difference may be explained by greater availability of public drug coverage among people more than 65 years of age and by the fact that, like our study, many studies have found that older patients are more likely to adhere with medications compared with younger patients. ${ }^{15,16}$ Similar to our study, many other studies have found lower income and poor health status to be associated with greater likelihood of costrelated nonadherence. ${ }^{15,16}$

In the Canadian context, increased compliance to prescribed medications among older populations may be explained, in part, by criteria for eligibility of prescription drug coverage programs across provinces. For Canada as a whole, we found a much higher rate of cost-related nonadherence among people aged 55-64 years than among people aged 65 years and older. In several provinces, access to public drug coverage increases substantially at 65 years of age, which may be partially responsible for the lower rates of cost-related nonadherence we saw among people in that age group. Greater public coverage for populations aged 65 years and older in Canada may also explain why lower income was not a significant determinant of cost-related nonadherence for that

\begin{tabular}{|c|c|c|c|}
\hline & All ages & Age $55-64$ yr & Age $\geq 65 \mathrm{yr}$ \\
\hline Characteristic & OR $(95 \% \mathrm{Cl})$ & OR $(95 \% \mathrm{Cl})$ & OR $(95 \% \mathrm{Cl})$ \\
\hline \multicolumn{4}{|l|}{ Age, yr } \\
\hline $55-64$ & $3.13(2.27-5.40)$ & - & - \\
\hline$\geq 65$ (reference) & 1.00 & & \\
\hline \multicolumn{4}{|l|}{ Sex } \\
\hline Male & $0.86(0.66-1.08)$ & $0.82(0.57-1.17)$ & $0.87(0.60-1.28)$ \\
\hline Female (reference) & 1.00 & 1.00 & 1.00 \\
\hline \multicolumn{4}{|l|}{ Health status } \\
\hline Fair or poor & $1.75(1.12-2.38)$ & $1.48(1.02-2.16)$ & $2.44(1.46-4.07)$ \\
\hline Good & $1.38(1.27-1.60)$ & $1.31(0.88-1.93)$ & $1.61(0.98-2.63)$ \\
\hline $\begin{array}{l}\text { Excellent or very good } \\
\text { (reference) }\end{array}$ & 1.00 & 1.00 & 1.00 \\
\hline \multicolumn{4}{|l|}{ Income } \\
\hline Low income & $3.59(2.32-5.55)$ & $4.32(2.63-7.09)$ & $2.27(0.90-5.58)$ \\
\hline Average income & $1.57(0.93-2.48)$ & $1.55(0.80-2.52)$ & $1.58(0.82-2.67)$ \\
\hline High income (reference) & 1.00 & 1.00 & 1.00 \\
\hline \multicolumn{4}{|l|}{ Insurance } \\
\hline No & $2.33(1.56-3.10)$ & $2.49(1.76-3.52)$ & $2.04(1.38-3.02)$ \\
\hline Yes (reference) & 1.00 & 1.00 & 1.00 \\
\hline \multicolumn{4}{|l|}{ Province/region } \\
\hline $\begin{array}{l}\text { British Columbia and } \\
\text { Manitoba }\end{array}$ & $0.99(0.63-1.56)$ & $1.17(0.64-2.10)$ & $0.81(0.39-1.66)$ \\
\hline Alberta and Saskatchewan & $0.86(0.43-1.11)$ & $0.73(0.44-1.21)$ & $1.04(0.62-1.73)$ \\
\hline Quebec & $0.78(0.56-1.04)$ & $0.49(0.29-0.82)$ & $1.29(0.77-2.15)$ \\
\hline Atlantic provinces & $1.04(0.60-1.46)$ & $0.79(0.98-1.26)$ & $1.40(0.85-1.80)$ \\
\hline Ontario (reference) & 1.00 & - & - \\
\hline
\end{tabular}


age group but was a significant determinant among Canadians aged 55-64 years. An additional potential explanation for this observation is the stabilizing effect of pension incomes on low-income persons more than 65 years of age. ${ }^{18}$

\section{Limitations}

We drew on a telephone survey that covered a wide range of topics that concerned health care experiences. Because the response rate was only $28 \%$, a participation bias could have occurred. Although the direction of bias is unknown, the sample weighting developed for this survey should address concerns that the respondents were not representative of the sociodemographic profile of the target population (people aged $\geq 55 \mathrm{yr}$ and living in the community). Telephone survey data are also limited by recall bias and potential social desirability bias. We do not believe that differences in such recall biases would be sufficient to drive regional and socioeconomic differences in prevalence of cost-related nonadherence within Canada.

Because the Canadian population is highly concentrated in a small number of provinces - the 5 smallest provinces account for less than $10 \%$ of the Canadian population - our samples for some provinces were small, despite the relatively large national sample for Canada in this international survey. To power comparisons across some provinces, we had to follow previous analyses that combined some provinces into groups based on a combination of geography and public drug coverage. ${ }^{10,12}$ This approach is not ideal, especially for the more disparate Atlantic provinces. However, this approach is defensible for the largest comparators (Ontario, Quebec, British Columbia and Manitoba, and Alberta and Saskatchewan) based on the structure of benefits offered to older residents in those provinces and province pairs. For similar reasons, the territories - which are home to less than $0.5 \%$ of Canada's population - are not included in our analysis.

Finally, the sample size in this study was not sufficient for subgroup analysis such as analysis of respondents with specific chronic conditions. That could be addressed in future research through a larger survey, potentially one linked to administrative records that provide more detailed and reliable information on health services use.

\section{Conclusion}

The financial accessibility of prescription medicines still is a substantial public health issue in Canada that affects 1 in 12 Canadians aged 55 years and older. Older Canadians at greatest risk of cost-related nonadherence to prescribed treatments are those with low incomes and those without private insurance to cover the costs not covered by public programs.

\section{References}

1. Medicines in bealth systems: advancing access, affordability and appropriate use. Geneva: World Health Organization; 2014.

2. Stanbrook MB, Hébert PC, Coutts J, et al. Can Canada get on with national pharmacare already? CMA7 2011;183:E1275.

3. Barnes S, Anderson L. Low earnings, unfilled prescriptions: employer-provided bealth benefit coverage in Canada. Toronto: Wellesley Institute; 2015.

4. Adams AS, Soumerai SB, Ross-Degnan D. The case for a medicare drug coverage benefit: a critical review of the empirical evidence. Annu Rev Public Health 2001;22:49-61.

5. Eaddy MT, Cook CL, O'Day K, et al. How patient cost-sharing trends affect adherence and outcomes: a literature review. P\&T 2012;37:45-55.

6. Tamblyn R, Laprise R, Hanley JA, et al. Adverse events associated with prescription drug cost-sharing among poor and elderly persons. $7 A M A$ 2001;285:421-9.

7. Goldman DP, Joyce GF, Zheng Y. Prescription drug cost sharing: associations with medication and medical utilization and spending and health. 7AMA 2007;298:61-9.

8. Kesselheim AS, Huybrechts KF, Choudhry NK, et al. Prescription drug insurance coverage and patient health outcomes: a systematic review. Am $\mathcal{F}$ Public Health 2015;105:e17-30.

9. Law MR, Cheng L, Dhalla IA, et al. The effect of cost on adherence to prescription medications in Canada. CMA7 2012;184:297-302.

10. Kennedy J, Morgan S. A cross-national study of prescription nonadherence due to cost: Data from the joint Canada-United States survey of health. Clin Ther 2006;28:1217-24.

11. Kennedy J, Morgan S. Health care access in three nations: Canada, insured America, and uninsured America. Int 7 Health Serv 2006;36:697-717.

12. Kennedy J, Morgan S. Cost-related prescription nonadherence in the United States and Canada: A system-level comparison using the 2007 international health policy survey in seven countries. Clin Ther 2009;31:213-9.

13. Osborn R, Moulds D, Squires D, et al. International survey of older adults finds shortcomings in access, coordination, and patient-centered care. Health Aff (Millwood) 2014;33:2247-55.

14. 2014 International Health Policy Survey of Older Adults. SSRS; 2014. Available: www.commonwealthfund.org/ /media/files/surveys/2014/2014-ihp -questionnaire_final.pdf (accessed 2016 Oct. 25).

15. Briesacher BA, Gurwitz JH, Soumerai SB. Patients at-risk for cost-related medication nonadherence: a review of the literature. 7 Gen Intern Med 2007;22:864-71.

16. Jin J, Sklar GE, Min Sen Oh V, et al. Factors affecting therapeutic compliance: A review from the patient's perspective. Ther Clin Risk Manag 2008; 4:269-86.

17. Andersen RM. Revisiting the behavioral model and access to medical care: does it matter. F Health Soc Behav 1995;36:1-10.

18. LaRochelle-Côté S, Myles J, Picot WG. Replacing family income during the retirement years: How are Canadians doing? Ottawa: Statistics Canada, Social Analysis Division; 2010.

Affiliations: School of Population and Public Health, University of British Columbia, Vancouver, BC

Contributors: Augustine Lee assisted with study design, analysis of data, interpretation of results, and preparation of the draft manuscript. Steve Morgan is responsible for study concept and design, interpretation of results, preparing components of the draft manuscript and revision of the manuscript for important intellectual content. Both of the authors approved the final version to be published and agreed to act as guarantors of the results.

Funding: This work was supported in part by the Canadian Institutes of Health Research (grant no. CIHR DCO150GP). The funding agency had no role in study design, analysis or preparation of the paper.

Supplemental information: For reviewer comments and the original submission of this manuscript, please see www.cmajopen.ca/content/5/1/ E40/suppl/DC1 